\section{Imaginary hazards?}

SIR - A recent leading article ("Ethical problems to merit the name", Nature 352, 359-60; 1991) gave a provocative, profound and largely accurate perspective on the 'industry' consisting of committees performing ethical enquiries pertaining to the new biology. Correctly, it took them - and implicitly, society to task for routinely defining contemporary ethical dilemmas as novel while neglecting essential corollaries to earlier controversies that have been addressed and reconciled. However, in one small respect, we would argue that the article has perpetrated just what it decries, by implying that any possible "environmental consequences if [genetically] altered organisms are more generally released" are somehow unique to or are more likely with the new biology. Given the ubiquity and impressive safety record of genetically improved - even 'transgenic' - organisms and the fundamental equivalence of old and new techniques of genetic manipulation, one is led to wonder, more generally released than what?

Two landmark documents from the US National Academy of Sciences (NAS) and the National Research Council (NRC) yield important scientific insights into this question. The NAS white paper $^{1}$ concluded that (1) "there is no

\section{OSI procedures}

SIR - In her recent article (Nature 352, $563 ; 1991)$, Barbara Culliton writes that "Hadley . . . has explicitly told scientific groups that she finds intent irrelevant in identifying misconduct". I have not made this assertion, nor do I believe that it is true. What I have said, based on counsel of the National Institutes of Health (NIH) Legal Advisor, is that proof of intent is not necessary to a finding of scientific misconduct; the commission of acts proscribed by Public Health Service (PHS) regulations is itself sufficient for a finding that scientific misconduct has occurred.

She asserts that "Hadley's organizing principle for the OSI" (Office of Scientific Integrity) was to "keep . . . allegedly damaging data secret, available to the accused only in summary form". This assertion is flatly incorrect. I always followed PHS Policies and Procedures (Federal Register 56, 13 June 1991, page 27388), which state that subjects of an inquiry or investigation "are provided access to any research data under review... [and] are provided with an opportunity to review and comment on significant investigatory documents ....". evidence of the existence of unique hazards either in the use of rDNA techniques or in the movement of genes between unrelated organisms"; (2) "[t]he risks associated with the introduction of rDNA-engineered organisms are the same in kind as those associated with the introduction of unmodified organisms and organisms modified by other methods"; and (3) "[a]ssessment of risks associated with introducing recombinant DNA organisms into the environment should be based on the nature of the organism and of the environment into which the organism is to be introduced," and independent of the method of engineering per se. In a more comprehensive treatment of this subject ${ }^{2}$, the NRC committee agreed that "no conceptual distinction exists between genetic modification of plants and microorganisms by classical methods or by molecular techniques that modify and transfer genes," whether in the laboratory, in the field, or in large-scale environmental introductions. The report emphasized the vast experience gained from routine field trials of plants modified by these older genetic methods, noting than "an individual corn, soybean, wheat, or potato breeder may introduce into the field 50,000 genotypes per year on average or $2,000,000$ in a career." And as reported

Culliton also asserts that the "OSI's definition of due process ..." expressly denies the accused the right to see at first hand all of the evidence against him or her". As I have said, this assertion is not correct. The only instance of which I am aware in which there was any departure from PHS policy occurred when the OSI did not have possession or control of certain pieces of evidence.

Culliton states that NIH Director Bernadine Healy "is distressed that Hadley ... blocked the early release of the Gallo report to an advisory committee that was not duly constituted". Even Healy has not made such an allegation, and in any case it is entirely false.

SuZANNE W. HADLEY (Special Assistant, Office of the Director) Office of Science Policy and Legislation, National Institutes of Health, Bethesda, Maryland 20892, USA

Barbara Culliton writes: Why, if damaging data are so faithfully provided, do so many scientists and their lawyers complain of secrecy?

But on the last point, Hadley is correct: the release of the Gallo report to the Richards committee was blocked by Healy, not Hadley, one reading of an ambiguous sentence. by Goodman et al. $^{3}$, many crops commonly grown and consumed in the United States - including oats, tomatoes, potato, wheat, rice and maize - have resulted from interspecific or intergeneric gene transfer, yielding 'genetically altered' and 'transgenic' plants by any reasonable definition. Hence, we return to the question, more generally released than what? Than the hundreds of millions of acres already planted with 'transgenic' (but non-'recombinant') plants, perhaps.

We suggest that some concerns about research or commercial introductions of organisms - such as the use of pathogenic or invasive species - are justified but are not new or unique to the new biology and that, in fact, organisms manipulated with the newest, most precise, most predictable techniques are even less likely to cause problems. Application of the new biology is not ethically daring, to use Nature's phrase, but logic and common sense applied to society's scientific questions seem increasingly to be.

HenRy I. Miller

Office of Biotechnology,

Food and Drug Administration

Rockville, Maryland 20857, USA

SUSANNE L. HUTTNER

University of California,

Systemwide Biotechnology Program, University of California, Los Angeles, Los Angeles, California 90024, USA

1. Introduction of Recombinant DNA-Engineered Organisms into the Environment: Key Issues (National Academy Press, Washington, D. C. 1987).

2. Field Testing Genetically Modified Organisms Framework for Decisions (National Academy Press, Washington, DC, 1989).

3. Goodman, R. M. Hauptli, H. Crossway, A. \& Knauf, V. C. Science 236, 48-54 (1987)

\section{Flare path}

SIR - In describing the Japanese SolarA mission due for launch on 26 August 1991, to study solar flares (Nature 352, 96; 1991), David Swinbanks omitted to mention the substantial involvement of two British groups, University College London's Mullard Space Science Laboratory and the Space Science Department of the Rutherford Appleton Laboratory. These groups, together with US colleagues, are providing the Bragg crystal spectrometer to study the hightemperature plasma produced during solar flares.

Mullard Space Science Laboratory, University College London,

Holmbury St Mary,

Dorking, Surrey RH5 6NT, UK

A. M. CRUISE

J. LANG

Space Science Department,

Rutherford Appleton Laboratory,

Chilton, Didcot,

Oxfordshire OX11 00X, UK

NATURE · VOL 353 $\cdot 19$ SEPTEMBER 1991 